\title{
BMJ Open Ten-year inhospital mortality trends for patients with trauma in Japan: a multicentre observational study
}

\author{
Isao Nagata, ${ }^{1,2,3}$ Toshikazu Abe, ${ }^{1,4}$ Masatoshi Uchida, ${ }^{2}$ Daizoh Saitoh, ${ }^{5}$ \\ Nanako Tamiya ${ }^{1}$
}

To cite: Nagata I, Abe T, Uchida M, et al. Ten-year inhospital mortality trends for patients with trauma in Japan: a multicentre observational study. BMJ Open 2018;8:e018635. doi:10.1136/ bmjopen-2017-018635

- Prepublication history for this paper is available online. To view these files, please visit the journal online (http://dx.doi. org/10.1136/bmjopen-2017018635).

Received 11 July 2017 Revised 26 September 2017 Accepted 8 November 2017

Check for updates

${ }^{1}$ Department of Health Services Research, Faculty of Medicine, University of Tsukuba, Tsukuba, Japan

${ }^{2}$ Graduate School of

Comprehensive Human

Sciences, Majors of Medical

Sciences, University of Tsukuba,

Tsukuba, Japan

${ }^{3}$ Department of Critical Care

Medicine, Yokohama City Minato Red Cross Hospital, Yokohama, Japan

${ }^{4}$ Department of Emergency and Critical Care Medicine, Juntendo University Urayasu Hospital,

Urayasu, Japan

${ }^{5}$ Department of Traumatology and Emergency Medicine, National Defense Medical College, Tokorozawa, Japan

Correspondence to

Toshikazu Abe;

abetoshi111@gmail.com

\section{ABSTRACT}

Objectives Trauma is one of the main causes of death in Japan, and treatments and prognoses of these injuries are constantly changing. We therefore aimed to investigate a 10-year trend (2004-2013) in inhospital mortality among patients with trauma in Japan.

Design Multicentre observational study.

Setting Japanese nationwide trauma registry (the Japan Trauma Data Bank) data.

Participants All patients with trauma whose Injury Severity Score (ISS) were 3 and above, who were aged 15 years or older, and whose mechanisms of injury (MOI) were blunt and penetrating between 2004 and 2013 ( $n=90$ 833).

Outcome measures A 10-year trend in inhospital mortality.

Results Inhospital mortality for all patients with trauma significantly decreased over the study decade in our Cochran-Armitage test $(P<0.001)$. Similarly, inhospital mortality for patients with ISS 16 or more and patients who scored $50 \%$ or better on the Trauma and Injury Severity Score (TRISS) probability of survival scale significantly decreased $(\mathrm{P}<0.001)$. In addition, the OR for inhospital mortality of these three patient groups decreased yearly after adjusting for age, gender, MOI, ISS, Glasgow Coma Scale, systolic blood pressure and respiratory rate on hospital arrival in multivariable logistic regression analyses. Furthermore, inhospital mortality for patient with blunt trauma significantly decreased in injury mechanism-stratified Mantel-extension testing $(\mathrm{P}<0.001)$. Finally, multivariable logistic regression analyses showed that the $\mathrm{OR}$ for inhospital mortality of patients with ISS 16 and over decreased each year after adding and adjusting for means of transportation and usage of whole-body CT.

Conclusion Inhospital mortality for patients with trauma in Japan significantly decreased during the study decade after adjusting for patient characteristics, injury severity and the response environment after injury.

\section{INTRODUCTION}

Unintentional injury has been in fifth or sixth place in cause of death for over a decade in Japan. Additionally, unintentional injury is a leading cause of death for Japanese youth (ages 1-29 years). Mostly, unintentional injury includes trauma. ${ }^{1}$ Therefore, it is important to analyse patterns of injury and treatment

\section{Strengths and limitations of this study}

- We showed detailed trauma trends for these 10 years (2004-2013) using Japanese nationwide trauma registry data.

- We analysed inhospital mortality trends adjusting for patient characteristics, injury severity and the response environment after injury.

- We could not investigate regional and facility differences in our study.

to establish guidelines that can prevent trauma-related deaths.

Over the past 10 years, the causes of trauma have fluctuated with traffic accidents decreasing, but falls increasing. ${ }^{2}$ Proactive trauma education has improved; the Japan Advanced Trauma Evaluation and Care association was started in 2002 to create trauma treatment guidelines, develop the off-the-job training based on these guidelines and enact treatment that meets such standards. ${ }^{3}$ Also, the Japan Trauma Data Bank (JTDB) was established in 2003 by the Japanese Association for the Surgery of Trauma and the Japanese Association for Acute Medicine to improve and assure the quality of trauma care in Japan. ${ }^{4}$ Furthermore, there are important yearly advancements in trauma care that may improve outcomes.

On the other hand, in Japan, ageing has accelerated rapidly and the elderly comprise the majority of patients with trauma who die due to traffic accident-related trauma. ${ }^{5}$ This is supported by the literature; a systematic review and meta-analysis about older patients with trauma reported that older patients with trauma suffered higher mortality. ${ }^{6}$ With such a complex and fluctuating subject, it is important to continuously update and improve trauma guidelines to reflect changes in patient injury types and demographics.

However, long-term detailed analyses concerning trauma prognoses for Japanese 
patients are scarce in the literature. Annual fluctuations and critical turning points for patient with trauma prognoses are also unknown. Therefore, we aimed to investigate the trend in inhospital mortality for Japanese patients with trauma over a recent 10-year time period to indicate where improvements in future guidelines should be focused.

\section{METHODS}

\section{Study design and data source}

This was a multicentre retrospective observational study using JTDB data. The participation to the JTDB data collection started from 55 hospitals. Participant hospitals increased year over year, and a total of 221 hospitals, including $85 \%$ of tertiary emergency medical centres in Japan in March, 2013 ( $\mathrm{n}=259)$, participated in the JTDB data collection in March, 2013. The inclusion criteria for the JTDB was patients with trauma who had Injury Severity Score (ISS) of 3 or above. The JTDB collected prehospital and hospital information such as patient demographics, comorbidities, injury types, mechanisms of injury (MOI), means of transportation, vital signs, Abbreviated Injury Scale score, prehospital treatment, inhospital procedures and inhospital mortality. ${ }^{7}$

Because of the anonymous and retrospective nature of this study, the need for informed consent was waived.

\section{Patients selection}

We screened every patient who was registered in the JTDB from 1 January 2004 to 31 March 2013, and enrolled patients with trauma whose ISS were 3 or higher, who were 15 or more years old and whose MOI were blunt and penetrating traumas. Patients were excluded from analysis if they had out-of-hospital cardiopulmonary arrest (OHCA) (chest compression in prehospital setting, systolic blood pressure of $0 \mathrm{~mm} \mathrm{Hg}$ and pulse rate of
$0 /$ min at the scene). Also, we excluded any patients who had missing data for age, gender, MOI, Revised Trauma Score (RTS), Trauma and Injury Severity Score (TRISS), Glasgow Coma Scale (GCS), systolic blood pressure and respiratory rate on hospital arrival or mortality. Figure 1 shows participant selection data from this study.

\section{Data collection and end point}

The JTDB data included the following information: age, gender, means of transportation, mechanism of injury, injury mechanism of blunt trauma, ISS, RTS, TRISS, GCS, systolic blood pressure and respiratory rate on hospital arrival, usage of whole-body CT and interventional radiology (IVR) for abdomen and pelvis, hospital location, length-of-hospital stay, inhospital mortality and disposition at discharge. Injury mechanism of blunt trauma was classified as motor vehicles, motorcycles, bicycles, pedestrian accidents, falls from high place, falls down and falls at same level. Falls from high place were defined as free falls from high place like a building. Falls down were defined as falls from stair or slope.

The primary outcome of this study was the trend in inhospital mortality and the data collection endpoint was determined by the end of the Japanese fiscal year in March 2013 for a total of 10 years of data (2004-2013).

\section{Statistical analysis}

To reveal characteristics of patient demographics, backgrounds, examinations and treatments in relation to inhospital mortality and hospitalisation, non-normally distributed continuous data were presented as medians and IQR and categorical data were summarised as percentages with counts. As a primary analysis to find trends of inhospital mortality within the specified decade of data, the Cochran-Armitage test and multivariable logistic regression analyses were conducted. The CochranArmitage test is used to test for the trend among binominal

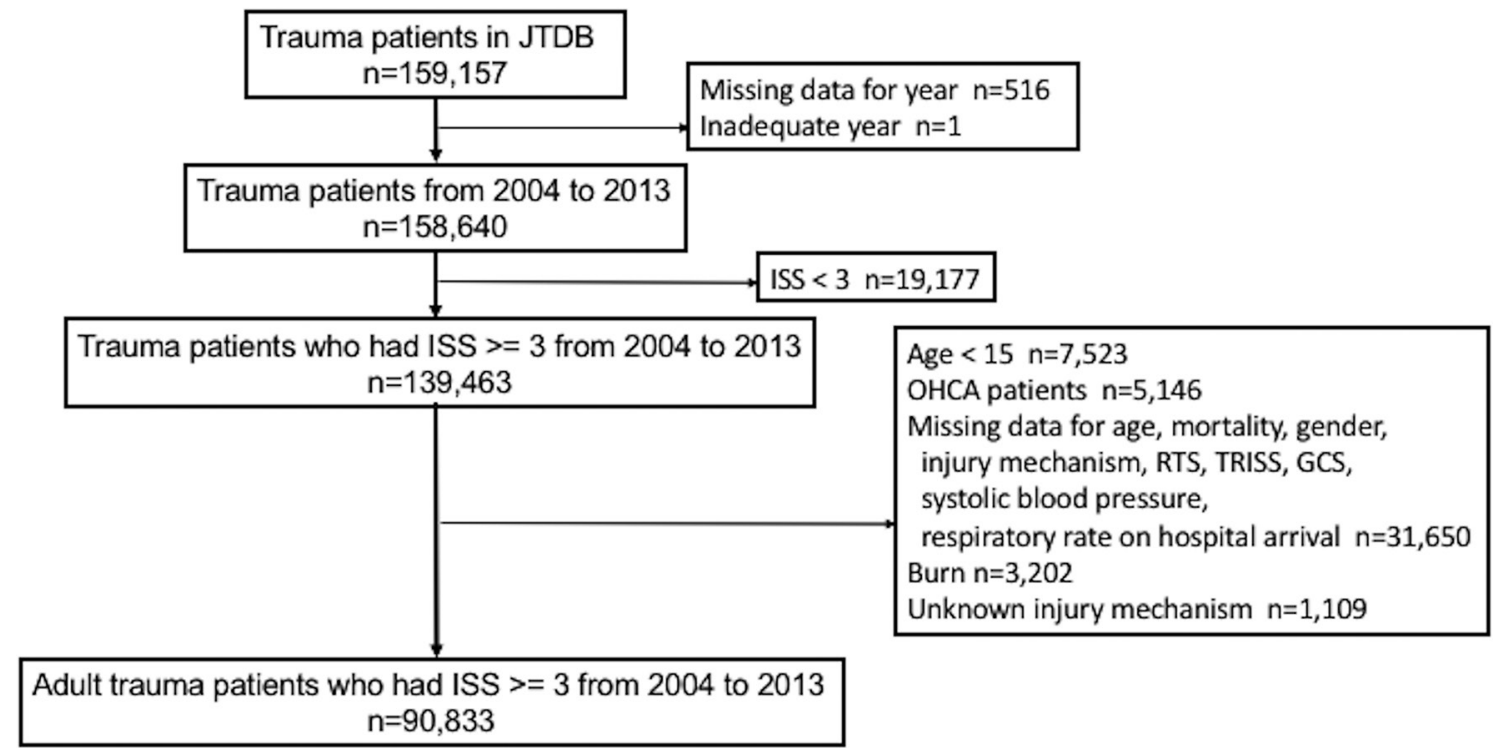

Figure 1 Patients flow chart. GCS, Glasgow Coma Scale; ISS, Injury Severity Scores; JTDB, Japan Trauma Data Bank; OHCA, out of hospital cardiopulmonary arrest; RTS, Revised Trauma Score; TRISS, Trauma and Injury Severity Score. 
proportions against ordinal explanatory variables. The following variables were applied to multivariable logistic regression analyses: age, gender, MOI, ISS, GCS, systolic blood pressure and respiratory rate on hospital arrival. In addition, the Cochran-Armitage test and multivariable logistic regression analyses were repeated for patients with ISS scores of 16 or higher and patients who scored $50 \%$ or better on the TRISS probability of survival scale. A three-step approach was used to analyse sensitivity. First, the Cochran-Armitage test was conducted among patients with trauma included any patients who had missing data to investigate the influence of it. Second, the Mantel-extension test was conducted to investigate the influence of injury mechanism blunt trauma on the 10-year trend in inhospital mortality. Last, a multivariable logistic regression analysis was repeated for patients with ISS scores of 16 or higher after adjusting for means of transportation and usage of whole-body CT in addition to the same variables as the primary analysis. Data are presented as ORs with 95\% CIs. P values for both the Cochran-Armitage and Mantel-extension tests were one sided, and $\mathrm{P}$ values for the multivariable logistic regression analyses were two sided. $\mathrm{P}<0.05$ was considered statistically significant. All analyses were performed using SAS V.9.4.

\section{RESULTS}

Out of a total of 159157 patients who were registered in the JTDB during the study period, 139463 patients with trauma who had ISS scores of 3 or higher from 2004 to 2013 were included. Cases were excluded if they were younger than 15 years old $(n=7523)$, if they had OHCA $(\mathrm{n}=5146)$ or if they had any missing data for age, gender, MOI, RTS, TRISS, GCS, systolic blood pressure and respiratory rate on hospital arrival and mortality $(n=31650)$. Exclusions were also made for burn $(n=3202)$ or if the cause of injury mechanisms was unknown $(\mathrm{n}=1109)$. After these adjustments, 90883 patients were eligible for inclusion in this study (figure 1).

Table 1 shows demographics and other data of patients with trauma by years. Mean age increased from 47 in 2004 to 64 in 2013, and rates in adult men showed a decreasing trend year by year. Helicopter transportation increased from $5.8 \%$ in 2004 to $8.0 \%$ in 2013 . The ratio of blunt trauma shifted into the higher $90 \%$ range over the entire decade of observation. With regard to injury mechanisms of blunt trauma, traffic accidents saw a decrease, and falls down/falls at same level showed a yearly increase in trend. Trauma severity scores like ISS and RTS, as well as TRISS probability of survival scores of less than $50 \%$, had a tendency to decrease.

Yearly examination, treatment and hospitalisation data are shown in table 2 . In the examination data, the performance rate of whole-body CT increase in all patients as well as patients with ISS scores of 16 or higher. With regard to treatment, the performance rate of abdominal and pelvic IVR fluctuated between $3 \%$ and $5 \%$ over the entire decade. For hospitalisation data, the rate of patients who were hospitalised in emergency and critical care centres decreased and the rate of general hospitalisation increased in a yearly fashion. The average length-of-hospital stay varied between 14 days and 18 days during the study period. Disposition at discharge classifications saw a steady trend of half the patients designated as 'home' and half designated as 'hospital transfer'.

The decade-long inhospital mortality trend is shown in figure 2 and table 3 . The results of Cochran-Armitage testing (figure 2) were that inhospital mortality for all patients with trauma significantly decreased over the study decade (from $15.8 \%$ in 2004 to $6.6 \%$ in 2013, $\mathrm{P}<0.001)$. Similarly, inhospital mortality for patients with ISS scores 16 or higher and patients with a $50 \%$ or better score on the TRISS probability of survival scale significantly decreased over the same period (from $28.5 \%$ in 2004 to $15.7 \%$ in 2013 among patients with ISS scores 16 or higher and from $8.4 \%$ in 2004 to $3.1 \%$ in 2013 among patients with a $50 \%$ or better score on the TRISS probability of survival scale, $\mathrm{P}<0.001)$. In multivariable logistic regression analyses with 2009 as the comparative control, all patients with trauma between 2004 and 2006 had higher ORs for inhospital mortality and those between 2011 and 2013 had lower ORs. In a similar comparison in patients with ISS scores of 16 or higher and patients with a $50 \%$ or better TRISS score, we saw a higher OR for inhospital mortality from 2004 to 2006 versus those from 2011 to 2013 when 2009 was used as the baseline.

With respect to sensitivity, the result of Cochran-Armitage testing conducted among patients with trauma included any patients who had missing data $(n=112303)$ was that inhospital mortality significantly decreased over the study decade (from $15.2 \%$ in 2004 to $6.6 \%$ in 2013, $\mathrm{P}<0.001)$. In addition, the result of injury mechanism-stratified Mantel-extension testing was that inhospital mortality for patients with blunt trauma significantly decreased over the study decade $(\mathrm{P}<0.001)$. Although means of transportation and usage of whole-body CT variables were included in our multivariable logistic regression analyses, yearly ORs for inhospital mortality among patients in the ISS 16 or higher classification did not change significantly compared with primary analyses (table 4).

\section{DISCUSSION}

\section{Brief summary}

In this study, we saw a significant yearly decrease in inhospital mortality for all patients with trauma in Japan over the study decade. Similarly, inhospital mortality for patients with ISS 16 or more and patients with a $50 \%$ or better score on the TRISS probability of survival scale significantly decreased each year. In addition, multivariable logistic regression analyses saw decreasing ORs for inhospital mortality of these three patient groups each year after adjusting for age, gender, MOI, ISS and vital signs. 


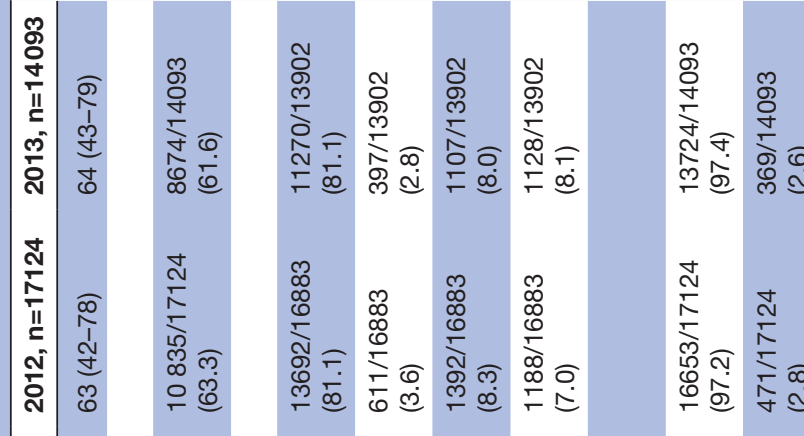

ᄒ⿱宀

吾

蒫

กับ

$\stackrel{\infty}{\stackrel{\infty}{\circ}}$

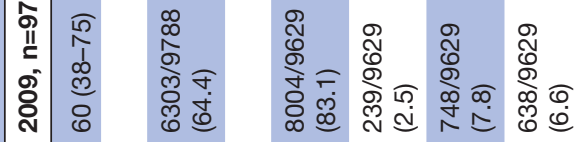

ชิ

II

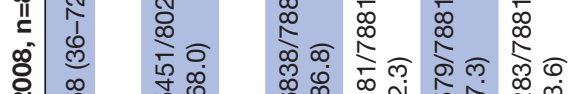

i⿱⺈

ֻ

ลे

है

8

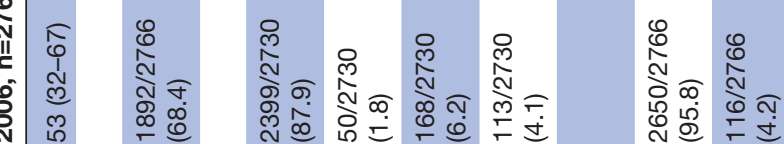

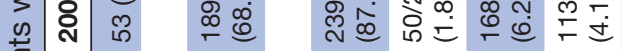

䓀

पั

苋

产

ट

- $\infty$

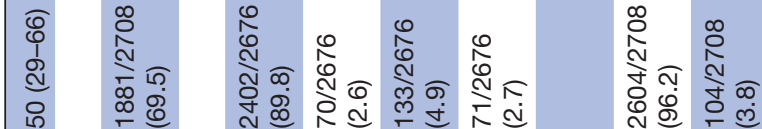

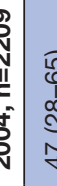

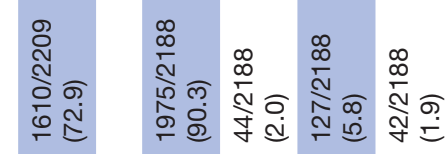

กิก

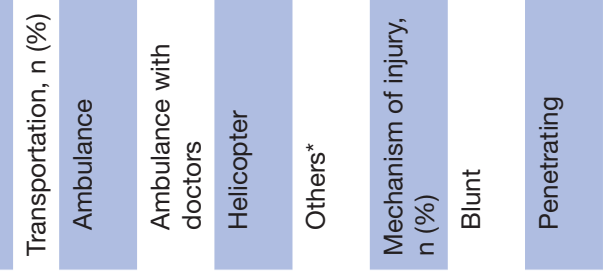

8

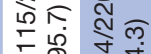

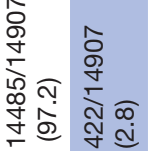

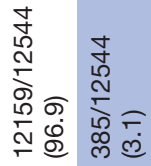

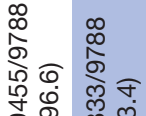

ఖి

象占

竞

要它

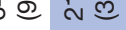

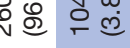

○

告

它

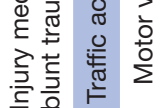

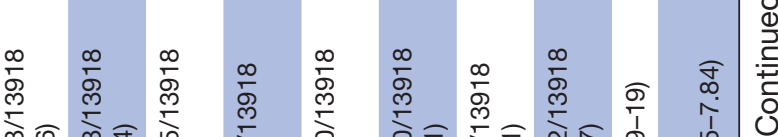

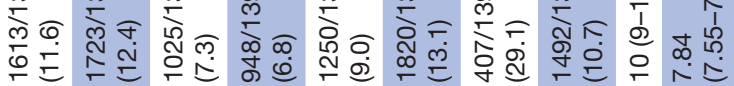

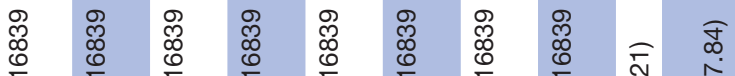

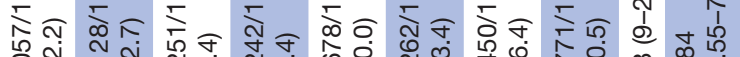

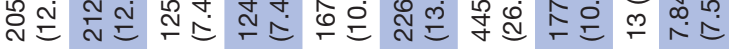

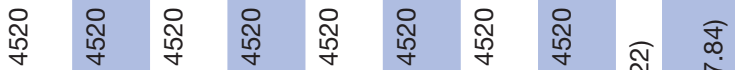

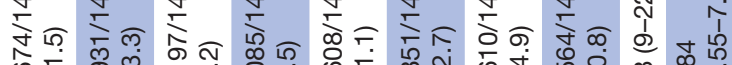

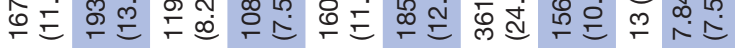

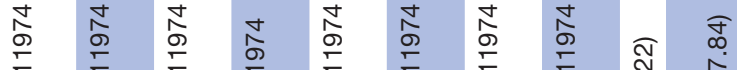

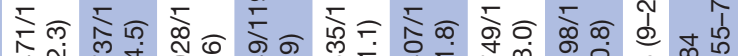

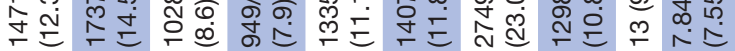

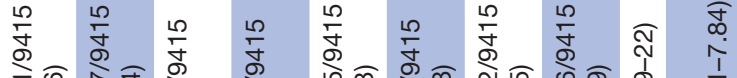
产过寺它

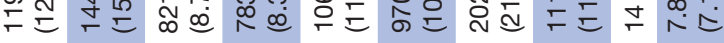

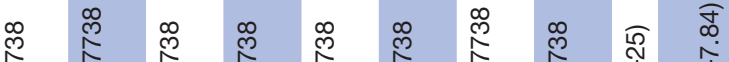

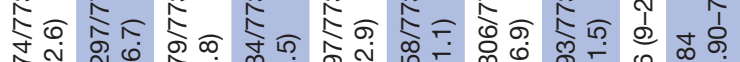

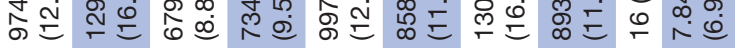

ชั

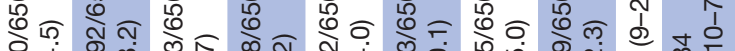

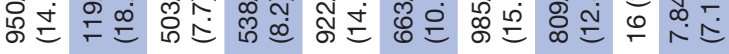

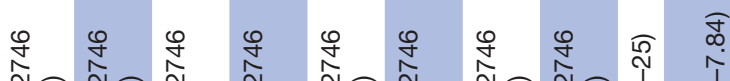

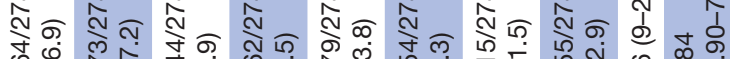

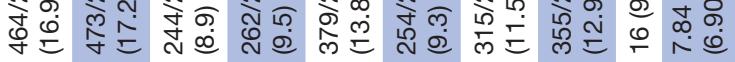

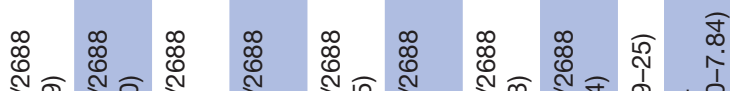
㝕

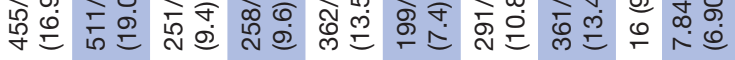

汹

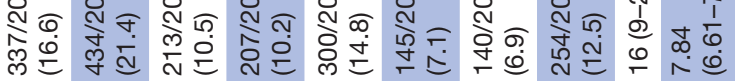

$\stackrel{0}{\mathbb{D}}$ 


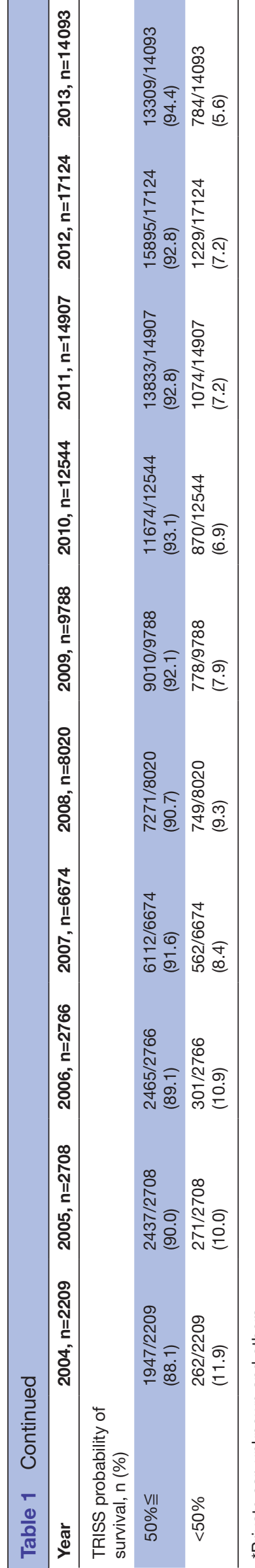

Relationship to previous studies

Our results are in accordance with several observational studies that reported trends in inhospital mortality for patients with trauma. ${ }^{8-13}$ A retrospective cohort study from Israel reported that inhospital mortality of patients with ISS scores of 16 or higher decreased significantly from $22 \%$ in 2000 to $16 \%$ in 2010 and that the OR for inhospital mortality in 2010 compared with 2000 was 0.53 , confirming a downward trend. The authors mentioned that establishment of a trauma response system brought a significant decrease in inhospital mortality although any single factor that explained the reduction was not identified. ${ }^{8}$ A retrospective study performed in New South Wales, Australia used multivariable logistic regression analyses to show that the OR for inhospital mortality of patients with an ISS score higher than 15 in 2007 compared with 2003 was 0.71 and that the OR for inhospital mortality was significantly lower among patients receiving definitive care at level I trauma centres compared with regional trauma centres. ${ }^{9}$ Also, in Japan, a retrospective observational study reported that adjusted inhospital trauma mortality was significantly lower in patients from 2009 to 2011 than from 2004 to 2006 (OR 0.64 in 2009-2011 compared with 2004-2006) possibly due to establishment of trauma education. ${ }^{10}$ In previous studies, it was mentioned that changes in the trauma response system, such as establishment of trauma education in the hospitals where patients were transported, contributed to the decrease in inhospital mortality. However, it is difficult to explain reductions of inhospital mortality with any single factor.

Our results showed changes in the injury mechanisms within the blunt trauma category. Traffic accidents had a tendency to decrease, and falls down/ falls at same level showed a yearly increase in trend. A previous study reported that the inhospital mortality OR of fall victims were lower than that of motor vehicle crash (MVC) victims in a multivariable logistic analysis (OR 0.60 in fall, reference in MVC).${ }^{14}$ Changes in the injury mechanisms within the blunt trauma category might contribute to reductions of inhospital mortality in our study. Therefore, we conducted an injury mechanism-stratified Mantel-extension test for blunt trauma and investigated the relationship between year and inhospital mortality among patients with blunt trauma. However, inhospital mortality for patients with blunt trauma significantly decreased each year after stratifying for injury mechanism, and we noticed that this stratification did not affect trends in inhospital mortality with respect to this test. In addition, our study investigated changes in emergency transportation methods and CT imaging methods because previous studies reported that helicopter transportation and usage of whole-body CT were associated with improvement in mortality among severe patients with trauma. ${ }^{15-18}$ Emergency transportation by helicopter and usage of whole-body CT tended to increase over the study decade, and we noted that helicopter transportation had lower ORs for inhospital mortality compared 


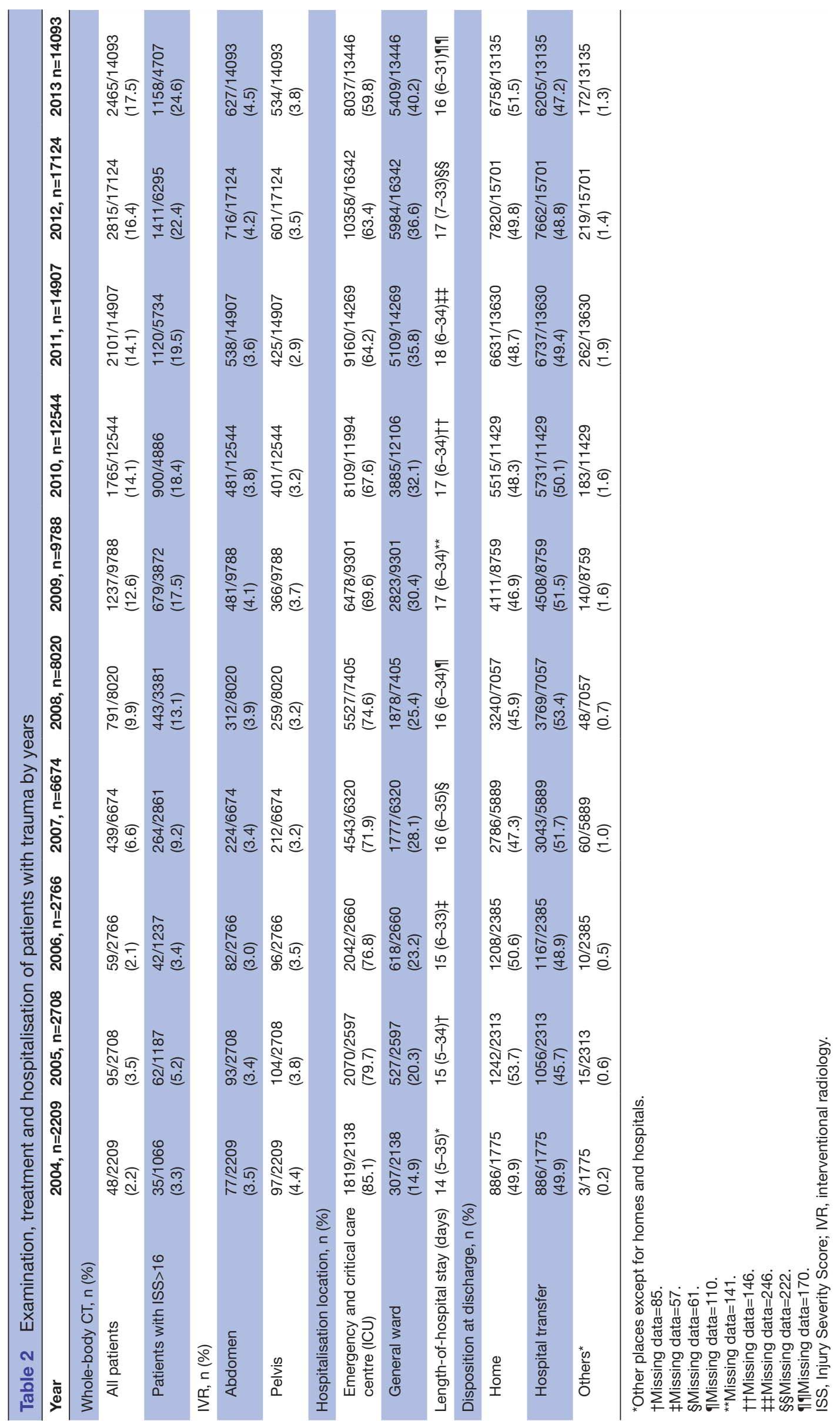




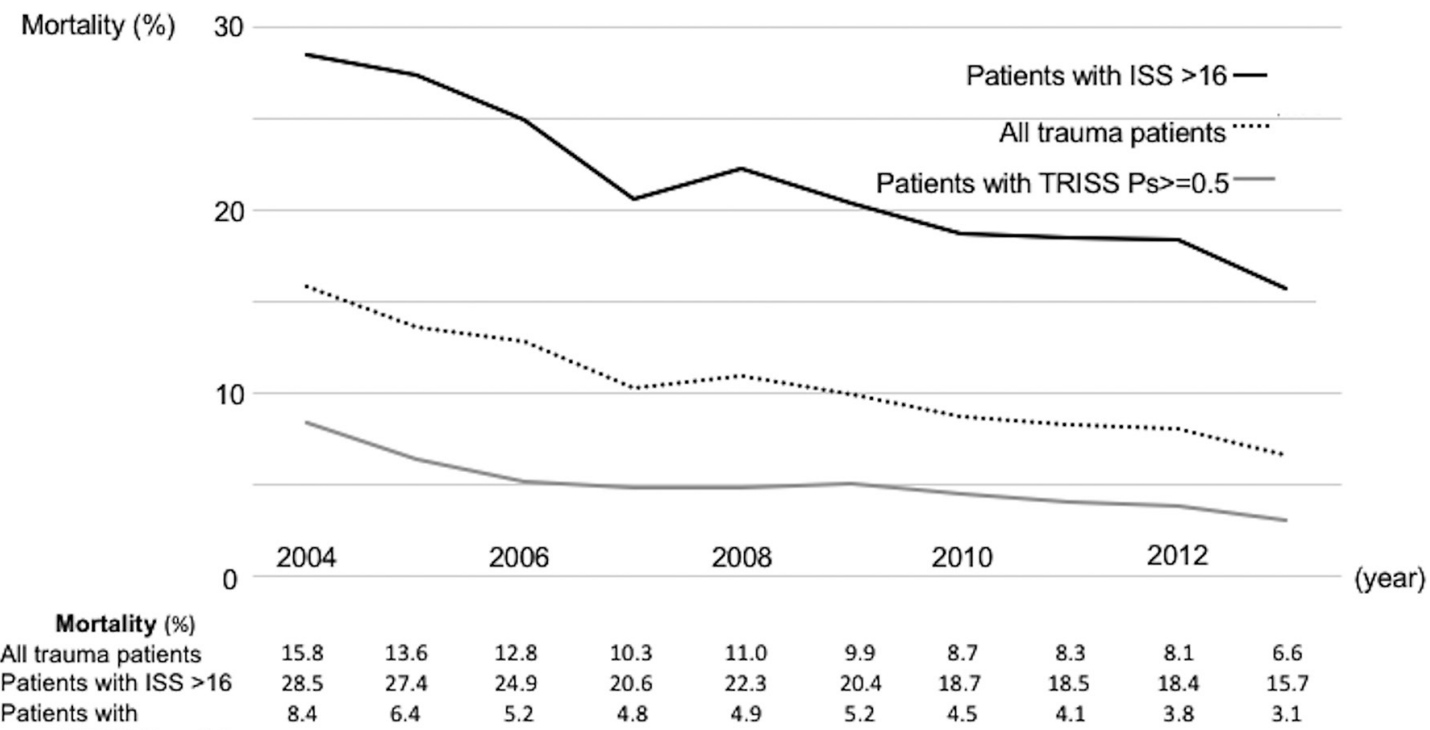

Figure 2 Ten-year inhospital mortality trends for patients with trauma. ISS, Injury Severity Scores; TRISS Ps, Trauma and Injury Severity Score probability of survival.

with ambulance transportation among patients with ISS scores of 16 or higher. Whole-body CT was also associated with inhospital mortality decreases among patients with
ISS scores of 16 or higher. Even after adjusting for helicopter transportation and usage of whole-body CT, ORs for inhospital mortality of patients with trauma with ISS

Table 3 Multivariable logistic regression analysis for inhospital mortality of patients with trauma

All patients, $\mathrm{n}=90833$

Patients with ISS $>16, \mathrm{n}=35226$

Patients with TRISS probability of survival $\geq 0.5$, OR $(95 \% \mathrm{Cl}) \quad$ P value $\mathrm{OR}(95 \% \mathrm{Cl}) \quad$ P value $\quad$ OR $(95 \% \mathrm{Cl}) \quad P$ value

Age $\quad 1.04(1.04$ to 1.04$) \quad<0.001 \quad 1.04(1.03$ to 1.04$) \quad<0.001 \quad 1.05(1.05$ to 1.05$) \quad<0.001$

Gender

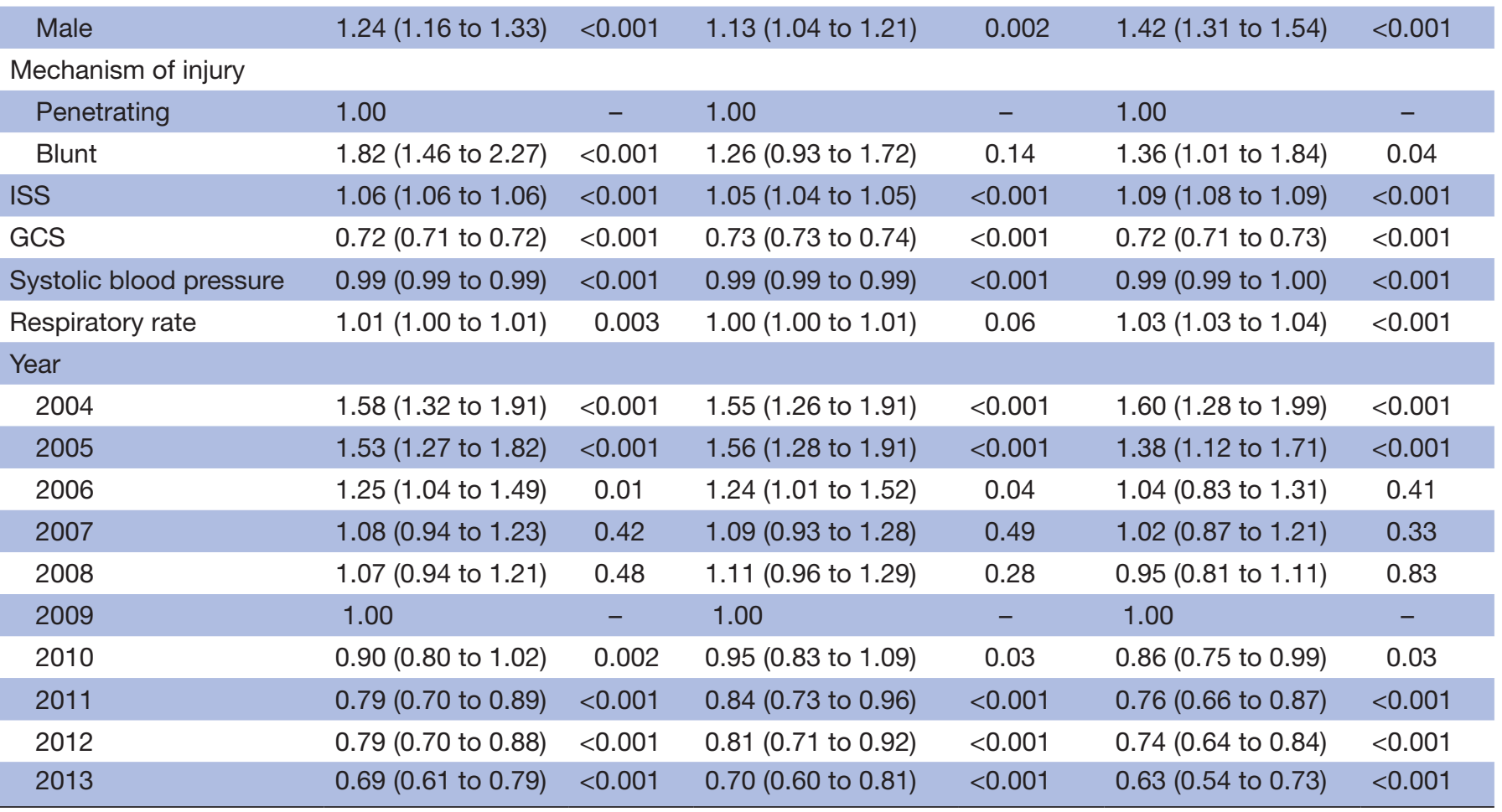

GCS, Glasgow Coma Scale; ISS, Injury Severity Score. 
Table 4 Multivariable logistic regression analysis for inhospital mortality of patients with trauma with ISS $>16$ $(n=34764)$

\begin{tabular}{|c|c|c|}
\hline & OR $(95 \% \mathrm{Cl})$ & $P$ value \\
\hline Age & $1.04(1.03$ to 1.04$)$ & $<0.001$ \\
\hline \multicolumn{3}{|l|}{ Gender } \\
\hline Male & 1.14 (1.05 to 1.23$)$ & 0.001 \\
\hline \multicolumn{3}{|l|}{ Mechanism of injury } \\
\hline Penetrating & 1.00 & - \\
\hline Blunt & $1.27(0.93$ to 1.73$)$ & 0.13 \\
\hline \multicolumn{3}{|l|}{ Transportation } \\
\hline Ambulance & 1.00 & \\
\hline Ambulance with doctors & $0.86(0.73$ to 1.01$)$ & 0.90 \\
\hline Helicopter & $0.70(0.63$ to 0.79$)$ & 0.02 \\
\hline Others* & 0.88 (0.64 to 1.20$)$ & 0.83 \\
\hline ISS & 1.05 (1.04 to 1.05$)$ & $<0.001$ \\
\hline GCS & $0.73(0.73$ to 0.74$)$ & $<0.001$ \\
\hline Systolic blood pressure & 0.99 (0.99 to 0.99$)$ & $<0.001$ \\
\hline Respiratory rate & $1.00(1.00$ to 1.01$)$ & 0.06 \\
\hline Whole-body CT & 0.91 (0.83 to 0.99$)$ & 0.04 \\
\hline \multicolumn{3}{|l|}{ Year } \\
\hline 2004 & $1.50(1.22$ to 1.85$)$ & $<0.001$ \\
\hline 2005 & $1.53(1.25$ to 1.88$)$ & $<0.001$ \\
\hline 2006 & $1.20(0.98$ to 1.48$)$ & 0.08 \\
\hline 2007 & $1.06(0.90$ to 1.24$)$ & 0.78 \\
\hline 2008 & $1.11(0.95$ to 1.29$)$ & 0.25 \\
\hline 2009 & 1.00 & - \\
\hline 2010 & 0.95 (0.82 to 1.09$)$ & 0.05 \\
\hline 2011 & 0.85 (0.74 to 0.97$)$ & $<0.001$ \\
\hline 2012 & $0.82(0.72$ to 0.93$)$ & $<0.001$ \\
\hline 2013 & 0.71 (0.61 to 0.82$)$ & $<0.001$ \\
\hline
\end{tabular}

*Private car, unknown and others.

GCS, Glasgow Coma Scale; ISS, Injury Severity Score.

scores of 16 or higher significantly decreased each year like primary outcome.

\section{Possible explanation and implications}

Various factors that influence outcomes for patients with trauma have been reported during the past decade: changes in trauma systems and emergency transportation by helicopter in prehospital settings ${ }^{15} 1619$ 20; usage of whole-body CT in examinations ${ }^{17}{ }^{18} 21$; tranexamic acid and damage control resuscitation including blood product ratio and massive transfusion protocols in treatment ${ }^{22-26}$; Advanced Trauma Life Support (ATLS) education $^{1027-29}$ and region/facility differentials. ${ }^{3031}$ However, it is controversial as to whether or not these factors improve outcomes for patients with trauma. Therefore, improvement of inhospital mortality in our study was considered to be due to a complex of changes in multiple factors.
Additionally, social policy might affect inhospital mortality. During our study period, laws requiring seatbelt usage in rear seats and strengthened penalties for drunken driving were established. ${ }^{32}$ Also, the improvement of motor vehicle engineering and safety devices might affect inhospital mortality. These changes have mainly affected the prevalence of certain trauma types and their severity (namely, MVC), as seen in our results, and such decreases in trauma severity which cannot be reflected in ISS and RTS might additionally contribute to changes in inhospital mortality.

Finally, we saw an increase in the mean age of patients with trauma from 47 to 64 . This seems to be supported by the well-reported demographic shift in Japan to an elderly society. As older adults are most likely to become victims of falls down or falls at same level (which we found to increase over the study period), our results may reflect the need for new guidelines for trauma care that focus specifically on the challenges of this trauma type. However, we controlled for age and other variables in our analyses, and still found the downward trend to be statistically significant. Age may continue to be a concern, however, and should be considered as an important variable in future studies.

Taken together, our results indicate a need to continuously monitor available long-term patient data in order to create detailed snapshots of trauma prognoses. A deeper understanding of the effect that complex variables such as education, means of transportation, age, injury type, and treatment type have on patient outcomes will give a solid foundation on which to build and refine future guidelines.

\section{Limitations}

Our study had several limitations. First, there was selection bias because all Japanese hospitals that treat trauma do not participate in the JTDB. Also, the number of participating hospitals differed across the study period. The severity of patients with trauma might differ by participating hospitals. However, most hospitals were tertiary emergency medical centres in Japan, where tertiary emergency medical centres defined by government. Therefore, participants in each year would be from similar environment. In addition, inhospital mortality of patients with trauma significantly decreased each year after adjusting for severity. Second, our study excluded a large number of patients with missing data $(n=31650)$. It might affect our outcome. However, the results of Cochran-Armitage testing were similar between study population without missing data and it included any patients who had missing data. Furthermore, we could not investigate regional and facility differences. However, our study was conducted using a nationwide database which had a large sample size to bolster our statistical analyses.

\section{CONCLUSION}

Our study has shown that inhospital mortality for patients with trauma in Japan significantly decreased over a 
10-year period (2004-2013) after adjusting for age and severity. The composite factors including improvement of medical care and services may contribute to reductions of inhospital mortality for patients with trauma, although further study is needed.

Acknowledgements The authors like to acknowledge Thomas D. Mayers and Bryan Mathis for his English-language manuscript revision.

Contributors IN conceived and designed this study, conducted data processing, analysed the data and wrote the manuscript. TA contributed to the conception and design of this study and drafted the manuscript. MU and NT contributed to design and critical revision of the manuscript. DS contributed to the acquisition of the data, study design and critical revision of the manuscript. All authors read and approved the final manuscript.

Funding This study was supported by the Ministry of Health, Labour and Welfare (H27-seisaku-senryaku-012).

Competing interests None declared.

Patient consent Detail has been removed from this case description/these case descriptions to ensure anonymity. The editors and reviewers have seen the detailed information available and are satisfied that the information backs up the case the authors are making.

Ethics approval The study protocol was reviewed and approved by the Ethical Committee of Yokohama City Minato Red Cross Hospital.

Provenance and peer review Not commissioned; externally peer reviewed. Data sharing statement № additional data are available.

Open Access This is an Open Access article distributed in accordance with the Creative Commons Attribution Non Commercial (CC BY-NC 4.0) license, which permits others to distribute, remix, adapt, build upon this work non-commercially, and license their derivative works on different terms, provided the original work is properly cited and the use is non-commercial. See: http://creativecommons.org/ licenses/by-nc/4.0/

(C) Article author(s) (or their employer(s) unless otherwise stated in the text of the article) 2018. All rights reserved. No commercial use is permitted unless otherwise expressly granted.

\section{REFERENCES}

1. Ministry of Health, Labour, and Welfare. Retrieved 27 Jun 2017. http://www.mhlw.go.jp/toukei/list/81-1a.html (In Japanese).

2. Ministry of Health, Labour, and Welfare. Retrieved 27 June 2017. http://www.mhlw.go.jp/toukei/saikin/hw/jinkou/tokusyu/furyo10/01. html (In Japanese).

3. JATEC. Retrieved 27 Jun 2017. http://www.jtcr-jatec.org/index_jatec. html (In Japanese).

4. Japan Trauma Data Bank. Retrieved 27 Jun 2017. http://www.jtcrjatec.org/traumabank/index.htm (In Japanese).

5. Cabinet Office, Government of Japan. Retrieved 27 Jun 2017. http:// www8.cao.go.jp/kourei/whitepaper/w-2015/html/gaiyou/s1_1.html (In Japanese).

6. Sammy I, Lecky F, Sutton A, et al. Factors affecting mortality in older trauma patients-A systematic review and meta-analysis. Injury 2016;47:1170-83.

7. Trauma registory. Trauma registory review board of the Japanese Association for the Surgery of trauma. Tokyo: Herusu Shuppan, 2013. (In Japanese).

8. Siman-Tov M, Radomislensky I, Peleg K. Reduction in trauma mortality in Israel during the last decade (2000-2010): the impact of changes in the trauma system. Injury 2013;44:1448-52.

9. Curtis KA, Mitchell RJ, Chong SS, et al. Injury trends and mortality in adult patients with major trauma in New South Wales. Med $J$ Aust 2012:197:233-7.

10. Hondo K, Shiraishi A, Fujie S, et al. In-hospital trauma mortality has decreased in Japan possibly due to trauma education. J Am Coll Surg 2013;217:850-7.
11. Di Saverio S, Gambale G, Coccolini F, et al. Changes in the outcomes of severe trauma patients from 15-year experience in a Western European trauma ICU of Emilia Romagna region (1996-2010). A population cross-sectional survey study. Langenbecks Arch Surg 2014;399:109-26.

12. Ruchholtz S, Lefering R, Paffrath $\mathrm{T}$, et al. Reduction in mortality of severely injured patients in Germany. Dtsch Arztebl Int 2008;105:225-31.

13. Moore L, Turgeon AF, Lauzier F, et al. Evolution of patient outcomes over 14 years in a mature, inclusive Canadian trauma system. World $J$ Surg 2015;39:1397-405.

14. Haider $\mathrm{AH}$, Chang DC, Haut ER, et al. Mechanism of injury predicts patient mortality and impairment after blunt trauma. J Surg Res 2009;153:138-42.

15. Galvagno SM, Haut ER, Zafar SN, et al. Association between helicopter vs ground emergency medical services and survival for adults with major trauma. JAMA 2012;307:1602-10.

16. Abe T, Takahashi O, Saitoh D, et al. Association between helicopter with physician versus ground emergency medical services and survival of adults with major trauma in Japan. Crit Care 2014;18:R146.

17. Caputo ND, Stahmer C, Lim G, et al. Whole-body computed tomographic scanning leads to better survival as opposed to selective scanning in trauma patients: a systematic review and metaanalysis. J Trauma Acute Care Surg 2014;77:534-9.

18. Jiang L, Ma Y, Jiang S, et al. Comparison of whole-body computed tomography vs selective radiological imaging on outcomes in major trauma patients: a meta-analysis. Scand J Trauma Resusc Emerg Med 2014;22:54.

19. Mckee JL, Roberts DJ, van Wijngaarden-Stephens MH, et al. The right treatment at the right time in the right place: a populationbased, before-and-after study of outcomes associated with implementation of an all-inclusive trauma system in a large Canadian province. Ann Surg 2015;261:558-64.

20. Twijnstra MJ, Moons KG, Simmermacher RK, et al. Regional trauma system reduces mortality and changes admission rates: a before and after study. Ann Surg 2010;251:339-43.

21. Sierink JC, Treskes K, Edwards MJ, et al. Immediate total-body CT scanning versus conventional imaging and selective CT scanning in patients with severe trauma (REACT-2): a randomised controlled trial. Lancet 2016;388:673-83.

22. Shakur H, Roberts I, Bautista R, et al. Effects of tranexamic acid on death, vascular occlusive events, and blood transfusion in trauma patients with significant haemorrhage (CRASH-2): a randomised, placebo-controlled trial. Lancet 2010;376:23-32.

23. Cannon JW, Khan MA, Raja AS, et al. Damage control resuscitation in patients with severe traumatic hemorrhage: A practice management guideline from the Eastern Association for the Surgery of Trauma. J Trauma Acute Care Surg 2017;82:605-17.

24. Zink KA, Sambasivan CN, Holcomb JB, et al. A high ratio of plasma and platelets to packed red blood cells in the first 6 hours of massive transfusion improves outcomes in a large multicenter study. $\mathrm{Am} \mathrm{J}$ Surg 2009;197:565-70. discussion.

25. Mitra B, O'Reilly G, Cameron PA, et al. Effectiveness of massive transfusion protocols on mortality in trauma: a systematic review and meta-analysis. ANZ J Surg 2013;83:918-23.

26. Valle EJ, Allen CJ, Van Haren RM, et al. Do all trauma patients benefit from tranexamic acid? J Trauma Acute Care Surg 2014:76:1373-8.

27. Navarro S, Montmany S, Rebasa P, et al. Impact of ATLS training on preventable and potentially preventable deaths. World J Surg 2014:38:2273-8.

28. Wang P, Li NP, Gu YF, et al. Comparison of severe trauma care effect before and after advanced trauma life support training. Chin $J$ Traumatol 2010;13:341-4.

29. Mohammad A, Branicki F, Abu-Zidan FM. Educational and clinical impact of Advanced Trauma Life Support (ATLS) courses: a systematic review. World J Surg 2014;38:322-9.

30. Jarman MP, Castillo RC, Carlini AR, et al. Rural risk: Geographic disparities in trauma mortality. Surgery 2016;160:1551-9.

31. Moore L, Evans D, Hameed SM, et al. Mortality in Canadian Trauma Systems: a Multicenter Cohort Study. Ann Surg 2017;265:212-217

32. Road Traffic Low. Retrieved 27 Jun 2017. http://law.e-gov.go.jp/ htmldata/S35/S35HO105.html (In Japanese). 